\title{
American College of Radiation Oncology (ACRO)
}

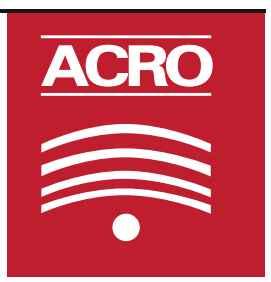

Published online: 19 August 2014

(C) Springer-Verlag Berlin Heidelberg 2014

The American College of Radiation Oncology (ACRO) is pleased to be able to call JRO its 'official journal' and to provide a subscription as one of many benefits of membership in the College. ACRO strives to ensure the highest quality care for radiation therapy patients and promote success in the practice of radiation oncology through education, responsible socioeconomic advocacy, and integration of science and technology into clinical practice. Membership is open to all radiation oncologists throughout the world, and colleagues who read this journal are invited to join the College and submit abstracts for the annual conferences, which are subsequently published in JRO. For more information go to www.acro.org.

This page is reserved for news and views from the American College of Radiation Oncology. The Editor of this page is A. Robert Kagan,MD, FACRO, a past president of the College and the long-time editor of The Bulletin, ACRO's quarterly Newsletter that ceased publication in 2012.

Note: The views expressed in the following editorial are not necessarily those of the American College of Radiation Oncology.

\section{The doctors know best... or do they? Kaganmd@aol.com}

Current management decisions are becoming over reliant on rules, depersonalized studies, and algorithms containing directions that may not apply to the patients we are seeing. Nevertheless, the patient is forced to fit in a template of treatments that are applied to all patients with a similar diagnosis and stage. This leads to excluding physician discretion, rejecting treatment modifications, and failing to discover what matters to the patient, in favor of recommending the so-called "best" treatment. This regimentation has resulted in removing caring and compassion from our practice and creating a gap between what the patient wants and what the doctor thinks the patient wants, inducing the physician to practice medicine in, according to Des Spence, "a persistent vegetative intellectual state."

The pernicious threat to the established order of personal experience is the RCT, which is not free from the risk of bias. It depends on populations and determines whether treatment A is better than treatment B. This is very important, crucial sometimes, but still the doctor should figure out whether his patient is similar to the patients in the RCT before opting for a management program, based on either treatment $\mathrm{A}$ or $\mathrm{B}$, both likely to be unsuitable as to the patient's age, medical condition, anticipated lifestyle change, problem with commuting, etc.

Our patients are often not a match for our education and further have had no medical experience. Nonetheless, they should be given enough information that is understood so that they can participate in the decisions for their treatment. More often, we talk over the patient's head, resulting in the patient feeling at least partially excluded from our decisions leading to their management. This oncobabble, often misunderstood by the patient if the doctor takes the time to ask, is a marketing strategy designed to convince the patient to do what the doctor wants for the patient. Surrounding every cancer is a patient. Our intention should be to offer the best treatment for the patient not merely a treatment for the cancer. Question your patient: what do you know, what do you want to know, and what have your doctors told you? The answers to these three questions will help you to define the "playing field," so that you will be able to personalize the informed consent and allow for the patients special wishes. No matter how the economics and the technology of health care may change, medicine will always come down to the bond between doctor and patient. 